\title{
A SOCIEDADE FLUMINENSE IMPERIAL: ESPAÇOS AMPLOS E RESTRITOS EM SONHOS D'OURO DE JOSÉ DE ALENCAR
}

\section{RIO'S IMPERIAL SOCIETY: HUGE AND NARROW SPACES IN SONHOS D'OURO BY JOSÉ DE ALENCAR}

\section{Divanize Carbonieri}

\author{
Doutora em Estudos Linguísticos e Literários em Inglês pela Universidade de São Paulo \\ Professora-adjunta da Universidade Federal de Mato Grosso \\ divacarbo@hotmail.com
}

\section{RESUMO}

No estudo do espaço ficcional em Sonhos d'ouro, um dos romances urbanos de José de Alencar, é possível vislumbrar a perspectiva que o autor apresenta a respeito da literatura brasileira. É também nessa obra que Alencar insere o famoso prefácio "Bênção paterna", em que examina as fases da literatura brasileira, posicionando seus romances de acordo com cada uma delas. $\mathrm{Na}$ terceira fase, aquela que ele considera o início de uma literatura nacional independente, estariam situados os retratos ficcionais que ele foi capaz de realizar da sociedade fluminense imperial, um contexto híbrido entre aspectos europeus e costumes locais. Dividindo o espaço romanesco em espaços amplos e restritos, o objetivo deste trabalho é estabelecer relações entre o espaço ficcional e as visões de Alencar a respeito da identidade nacional e da literatura brasileira.

Palavras-chaves: Espaço. Identidade Nacional. Literatura Brasileira. José de Alencar

\begin{abstract}
In the study of fictional space in Sonhos d'ouro, one of José de Alencar's urban novels, it is possible to identify the author's perspective concerning Brazilian literature. It is also in that work that Alencar inserts the famous preface "Bênção paterna", in which he examines the phases of Brazilian literature, classifying his novels according to each one of them. The fictional portraits he was able to create of Rio's imperial society, a hybrid context between European aspects and local customs, belonged to the third phase, which Alencar considers the beginning of an independent national literature. The aim of this paper is to establish relationships between the fictional space and Alencar's ideas about the national identity and Brazilian literature by dividing the analysis in huge and narrow spaces.
\end{abstract}

Key-words: Space. National Identity. Brazilian Literature. José de Alencar 


\section{INTRODUÇÃO}

Sonhos d'ouro (1872) é um romance de José de Alencar que vem acompanhado do prefácio "Bênção paterna", escrito pelo próprio autor. Nele, Alencar encena dirigir-se ao livro como se fosse um ente vivo e dotado de racionalidade, manifestando a intenção de prepará-lo para as críticas que estariam por vir. A principal censura, em sua visão, seria considerá-lo "demais arrebicado à estrangeira" (ALENCAR, s/d., p. 15). O modo de responder a isso é afirmar que seu romance é o "filho deste século enxacoco e mazorral, que tudo aferventa a vapor, seja poesia, arte, ou ciência" (ALENCAR, s/d., p. 15). Dessa forma, Alencar revela ter consciência de que sua obra é fruto de uma época e de um contexto repleto de processos de hibridismo, ou seja, o Rio de Janeiro oitocentista, então capital do Império, em que línguas e costumes estrangeiros se misturavam aos modos locais e as ideias de modernidade invadiam as artes e as ciências.

Mas Alencar defende-se da acusação de estrangeirismo exacerbado, dividindo a literatura brasileira - e a sua produção dentro dela - em três fases. A primeira fase corresponderia às narrativas lendárias e mitológicas oriundas das raízes indígenas do Brasil que permaneceriam na imaginação popular e seriam resgatadas pelos escritores preocupados com a identidade nacional. Nessa fase, Alencar situaria Iracema, romance em que ele retoma lendas da criação do Ceará e da miscigenação da população local. A segunda fase abrangeria as obras que dariam conta do período histórico da colonização portuguesa em terras brasileiras, retratando "o consórcio do povo invasor com a terra americana, que dele recebia a cultura, e lhe retribuía nos eflúvios de sua natureza virgem" (ALENCAR, s/d., p. 17). Fariam parte desse estágio os romances $O$ guarani e Minas de prata, que retratam a conquista do Brasil e a mistura de suas raças.

A terceira fase, por sua vez, seria classificada por Alencar como "a infância de nossa literatura", um momento em que a independência política do país deveria ser acompanhada por uma emancipação literária dos moldes estabelecidos pela literatura portuguesa. Nesse momento, Alencar enfatiza a necessidade de uma descolonização também da mente ou da imaginação, "fazendo calar as pretensões hoje tão acesas, de nos recolonizarem pela alma e pelo coração, já que não o podem pelo braço" (ALENCAR, s/d., p. 17). Além disso, as obras desse estágio assumiriam características relacionadas com dois contextos principais: aquele do interior do Brasil, "[o]nde não se propaga com rapidez a luz da civilização", e o da nova cidade, da corte, "que de dia em dia se modifica e se repassa do espírito forasteiro" (ALENCAR, s/d., p. 17). $O$ tronco do ipê, o Til e $O$ gaúcho surgiriam da configuração desse Brasil profundo enquanto que Senhora, Diva e o próprio Sonhos d'ouro apresentariam um cenário urbano e moderno. Para Alencar, 
[t]achar esses [últimos] livros de confeição estrangeira, é, relevem os críticos, não conhecer a fisionomia da sociedade fluminense, que aí está a faceirar-se pelas salas e ruas com atavios parisienses, falando a algemia universal, que é a língua do progresso, jargão erriçado de termos franceses, ingleses, italianos e agora também alemães (ALENCAR, s/d., p. 18).

Dessa forma, Sonhos d'ouro foi escrito, tendo como objetivo o retrato da vida carioca na segunda metade do século XIX. O espaço é apresentado como um importante elemento na sua construção narrativa. Uma razão para isso pode ser encontrada no fato de que o espaço materializa a relação entre a natureza e a cultura, desenhando um ambiente característico da corte imperial brasileira, em que luxuriantes paisagens se combinariam à vida sofisticada e europeizada da elite. Através do espaço, vislumbram-se alguns pontos de vista sobre a natureza nativa, a figura da mulher e a identidade nacional. Nesse sentido, não se pode entender o espaço como um ente acessório ou acidental da trama ficcional, mas como um componente que também exige análise e interpretação.

O enredo se passa principalmente na Tijuca durante o verão. Porém, o espaço retratado não nos interessa pela possível veracidade na representação da geografia, mas pela função que adquire em diferentes momentos da narrativa. O protagonista Ricardo é um jovem advogado que sai de São Paulo, onde deixa a mãe, a irmã e a noiva, indo para o Rio de Janeiro em busca de melhores oportunidades para ganhar dinheiro e quitar as dívidas da família. Na nova cidade, ele conhece Guida, filha do comendador Soares e uma das beldades mais ricas da corte, moça mimada e educada à moda inglesa. Pressionada a encontrar um futuro marido pelo pai, Guida escolhe Ricardo, não porque tenha se apaixonado por ele, mas apenas porque o acha gentil e confiável. Contudo, Ricardo, mesmo tentado, revela que já é comprometido. A partir dessa impossibilidade, Guida desperta para a paixão e se desespera verdadeiramente. Ricardo também sofre até que sua noiva Bela o dispense do compromisso e ele e Guida possam finalmente ficar juntos.

Nessa trama, portanto, amor e dinheiro se entrelaçam. É uma crítica talvez aos casamentos arranjados na época apenas por conveniência ou interesse material, mas não implica uma negação completa da importância do dinheiro para a felicidade conjugal. Ao mesmo tempo em que constitui uma exaltação aos sentimentos, o romance ressalta a importância da iniciativa individual na busca dos objetivos pessoais. Da mesma forma, a natureza e os ambientes sociais são importantes para o desenvolvimento do relacionamento entre os protagonistas e para fornecer um retrato da sociedade fluminense imperial, tal como Alencar desejava. O objetivo deste trabalho é justamente examinar alguns elementos que atuam na construção do espaço em Sonhos d'ouro. A exemplo de Antonio Candido (1972) em "Degradação do espaço", ensaio em 
que ele discorre sobre os ambientes em L'Assomoir de Émile Zola, dividiremos, para fins de análise, o espaço romanesco em duas espécies: os espaços amplos ou gerais e os espaços restritos ou particulares.

\section{ESPAÇOS AMPLOS}

A narrativa de Sonhos d'ouro se inicia com a seguinte descrição do espaço:

O sol ardente de fevereiro dourava as lindas serranias da Tijuca. Que formosa manhã! O céu arreava-se do mais puro azul; o verde da relva e da folhagem sorria entre as gotas de orvalho, cambiando aos toques da luz. Frocos de névoa, restos da cerração da noite cingiam ainda os píncaros mais altos da montanha, como pregas de véu flutuante, ao sopro da brisa, pelas espáduas das lindas amazonas que durante o verão costumam percorrer aquelas amenas devesas (ALENCAR, s/d, p. 21). ${ }^{1}$

O sol é o primeiro substantivo a aparecer no texto. É ele que brilha alto no céu da página, dourando a paisagem da Tijuca e indicando qual será a tonalidade dominante em Sonhos d'ouro, romance em que o amarelo (ou dourado) assume um papel tão fundamental. O ouro aparece até no título do livro e aí apresenta pelo menos dois significados: 1) está relacionado aos sonhos de riqueza do protagonista, o jovem Ricardo, e 2) é o nome que ele deu à singular flor amarela que encontrou na Tijuca e que acabou por aproximá-lo de Guida, em quem despertará a primeira paixão. Assim, o amarelo não simboliza apenas o aspecto material da riqueza, mas também a vitalidade da paixão amorosa.

Do dourado do sol, o narrador passa, ainda no primeiro parágrafo, para o "mais puro azul" do céu e para o "verde da relva e da folhagem". Em seguida, no segundo parágrafo, ele se detém nos "píncaros das montanhas mais altas". Dessa forma, o romance se inicia com o que parece ser um movimento circular dos olhos, do alto para baixo e depois novamente para o alto. Tal movimento da visão sobre a paisagem assinala a especificidade do romance, gênero baseado na individualidade e que ao mesmo tempo abarca em si um mundo. Nesse caso, o indivíduo estaria na posição daquele que olha, daquele que realiza tal movimento com os olhos. $\mathrm{O}$ movimento circular, por sua vez, apresenta um aspecto totalizante, apreendendo céus e terras num simples relance. O romance é uma perspectiva individual de uma realidade completa.

Ainda no segundo parágrafo e através da brisa, o narrador chega até as "lindas amazonas" que percorrem aquelas cercanias durante o verão. A mulher aparece, então, idealmente relacionada à natureza. O fato de o autor utilizar o substantivo "amazonas" ao invés de qualquer outro que indicasse a presença feminina parece ter inúmeros significados. Um deles se refere inegavelmente à classe social das jovens, uma vez que apenas moças ricas possuíam 
cavalos de montaria na época em que se passa o enredo. ${ }^{2}$ A classe social da mulher é, sem dúvida, um elemento importante numa narrativa em que os temas principais são o amor e a riqueza. Outra interpretação possível para a escolha dessa palavra é o fato de ela evocar uma atmosfera de beleza selvagem ideal e mítica em torno da figura da mulher. A própria natureza é vista idealmente como um ambiente gentil que possibilita idílicos encontros amorosos com essas amazonas.

Tal visão da natureza aproxima a narrativa da poética do pitoresco, característica do préromantismo. O termo pitoresco surgiu com o desenvolvimento da jardinagem na segunda metade do século XVIII, indicando um tipo de jardim em que a natureza era modelada racionalmente. Para o artista ligado à poética do pitoresco, a natureza deve ser modelada, como o que acontece com esses jardins, para produzir um ambiente agradável e acolhedor, favorável aos relacionamentos sociais e à convivência harmônica entre as pessoas.

O tema da natureza modelada pelas mãos do homem, domesticada, planejada vai aparecer novamente em Sonhos d'ouro, por exemplo, na descrição da Floresta da Tijuca, que é vista como o resultado ou a promessa do trabalho de um homem:

O nome pomposo do lugar não é por ora mais do que uma promessa; quando porém crescerem as mudas de árvores de lei, que a paciência e inteligente esforço do engenheiro Archer tem alinhado aos milhares pelas encostas, uma selva frondosa cobrirá o largo dorso da montanha, onde nascem os ricos mananciais (ALENCAR, s/d., p. 37).

A Tijuca, como dissemos anteriormente, é o espaço principal do romance. É nesse ambiente que encontros sociais e passeios vão acontecer entre os personagens, sobretudo entre Ricardo e Guida. Nesse caso, é evidente a preocupação em construir uma ambientação propícia a esses encontros e, por essa razão, muitos são os trechos em que a natureza da Tijuca é vista através das lentes da estética do pitoresco.

Assinalamos anteriormente a correlação entre as "lindas amazonas" e o ambiente gentil. A relação entre a natureza agradável e a mulher fica ainda mais evidente em outra passagem mais à frente:

Há cascatas muito mais ricas e abundantes do que essa, não só na grande massa das águas, como na vastidão e aspereza dos penhascos. Têm sem dúvida aspecto mais soberbo e majestoso; inspiram n'alma pensamentos mais graves e sublimes. A Cascatinha da Tijuca, porém, prima pela graça; não é esplêndida, é mimosa; em vez da pompa selvagem respira uma certa gentileza de moça elegante; bem se vê que não é uma filha do deserto; está a duas horas da corte, recebe freqüentemente diplomatas, estrangeiros ilustres e a melhor sociedade do Rio de Janeiro. Assim não se despenha ela com a fúria de uma serpente, mas com a indolência com que uma senhora da moda se derreia no recosto do divã. Sua voz não é um trovão, mas o rumorejo que embala docemente o coração (ALENCAR, s/d, p. 37). 
É possível notar o contraste que o narrador estabelece entre a natureza pitoresca (a "mimosa" cascatinha) e a natureza sublime, representada por cachoeiras maiores e mais abundantes, cujas águas batem com violência nas pedras, produzindo um som parecido com trovões. O sublime na representação da natureza se dá justamente nessa enormidade dos fenômenos naturais, diante dos quais a pequenez humana fica evidente. Recorrendo a Giulio Carlo Argan (1993), temos as bases para uma diferenciação entre a poética do pitoresco e a do sublime:

para o "pitoresco", a natureza é um ambiente variado, acolhedor, propício, que favorece nos indivíduos o desenvolvimento dos sentimentos sociais, para o "sublime", ela é um ambiente misterioso e hostil, que desenvolve na pessoa o sentido de sua solidão (mas também de sua individualidade) e da desesperada tragicidade do existir (ARGAN, 1993, 12).

Em Sonhos d'ouro, é o pitoresco e não o sublime que norteia em grande parte a visão sobre a paisagem. Contudo, a exemplo do que acontece com esse trecho sobre a Cascatinha da Tijuca, o sublime também surge na narrativa, sobretudo como elemento de comparação, de contraste. Mais adiante, o contrate aparece ainda mais bem delineado:

\begin{abstract}
Do lado que olha para o mar, a serra da Tijuca apresenta um aspecto muito diferente. As encostas que descem para o Andaraí, como os vales e eminências que se encontram pelo dorso da montanha. Têm a fisionomia risonha e pitoresca: são ondulações amenas ou recortes caprichosos, que deleitam a vista. $\mathrm{Na}$ outra face, a natureza é agreste; dir-se-ia uma terra convulsa. $\mathrm{O}$ fogo subterrâneo ferveu nas entranhas da terra, e rasgando-lhe os flancos, arremessou aqui e ali pelas encostas enormes calhaus ou maciços de rocha, fragmentos da primeira carcassa do globo (ALENCAR, s/d, p. 43).
\end{abstract}

$\mathrm{Na}$ passagem sobre a Cascatinha da Tijuca, a imagem usada para exemplificar o contraste entre pitoresco e sublime é a diferença entre dois tipos de mulher: a "filha do deserto" e a "moça elegante" da corte. No lugar da filha do deserto, também aparece a imagem da serpente. O deserto é um ambiente inóspito, que provoca no ser humano um sentimento de pequenez, de esmagamento, de aniquilação. Ele é capaz, então, de produzir no indivíduo, assim como as grandes cascatas que despencam com a força dos trovões, a experiência do sublime terrivel. ${ }^{3} \mathrm{~A}$ "filha do deserto" é vista como a mulher que compartilha com esse ambiente o mesmo perigo, daí sua aproximação com a serpente. Nesse sentido, a "moça da corte", indolente e suave, aparece como mais permissiva, mais favorável; o próprio modo como ela se recosta indolentemente no divã evoca uma atmosfera de sensualidade sem perigo, doméstica. E, assim como a "mimosa" cascatinha é mais adequada para estar entre "diplomatas, estrangeiros ilustres e a melhor sociedade do Rio de Janeiro", é a moça elegante a noiva mais indicada para aquele que deseja transitar por esse meio. 
Mas para que os encontros amorosos sejam possíveis, além do elemento feminino, é preciso que apareça na narrativa o masculino: "um passeador solitário seguia a pé e distraidamente por um dos muitos caminhos que se cruzam em várias direções pela encosta ocidental da montanha” (ALENCAR, s/d., p. 21).

Um pouco adiante, num diálogo entre ele e Fábio, ficamos sabendo que esse passeador solitário é Ricardo. Nesse momento, ele está num “dos muitos caminhos que se cruzam em várias direções". Um caminho indica dinamismo, possibilidade de movimento, ainda mais quando se cruza com outros em várias direções. Assim, Ricardo é apresentado inicialmente como alguém que está no centro de muitas possibilidades. Apesar de ainda não sabermos que se trata do protagonista, essa apresentação já nos assinala que se trata de alguém importante para a ação do romance.

Uma vez que anteriormente indicamos o significado da classe social presente em “amazonas", não podemos deixar de prestar atenção à expressão "seguia a pé". O passeador segue a pé (é, portanto, pobre, sem cavalo) no mesmo local em que passeiam lindas amazonas (abastadas). Assim, essas inúmeras possibilidades que os caminhos abrem para o passeador correspondem às chances que ele tem de encontrar pela frente alguma moça rica que mude o seu destino.

Mas quem está apenas a caminho, a rigor não está em lugar nenhum. É somente quando sai desse caminho e entra no mato (fazendo uma escolha ou simplesmente uma pausa?) que Ricardo encontra o arbusto de flores amarelas que dão nome ao livro. A flor é descrita como sendo sem perfume, portanto, segundo o narrador, sem coração. Em compensação, ela é comparada ao ouro pelo menos em dois aspectos: na cor e no formato dos botões, que se parecem com contas de ouro. Essa semelhança com o ouro estimula os sonhos de riqueza de Ricardo. Veremos mais tarde que também Guida é retratada como uma moça sem coração (significando que ainda não sentiu nenhuma paixão) e rica. Mais uma vez aparece uma relação entre a natureza e a mulher, dessa vez mais específica. Quando Ricardo vê Guida pela primeira vez, ela parece emoldurada por essa flor amarela:

\footnotetext{
Entre o arvoredo tecido de grinaldas amarelas aparecia uma esfera do azul do céu, como uma tela fina de um papel, cingido por medalhão de ouro. A sombra de uma nuvem errante infundia ao horizonte suave transparência. Debuxava-se na tela acetinada o vulto airoso de linda moça, que montava com elegância um cavalo isabel (ALENCAR, s/d., p. 25).
}

Novamente, surge a referência ao ouro. Sob a cabeça de Guida, o sol funciona como um "medalhão de ouro" e o "tecido de grinaldas amarelas" envolve a promessa de casamento, fazendo de Guida uma espécie de noiva dourada ou "d'ouro". Nessa primeira aparição de Guida, 
o narrador se demora em sua descrição física por pelo menos sete parágrafos. Ela é descrita como uma mulher de beleza ideal, sobre-humana, sendo mesmo comparada à estátua de Diana. Em todo o enredo, nenhuma mulher superará a beleza de Guida, nem mesmo Bela, a noiva paulista de Ricardo. Essa caracterização da personagem corresponde às demais caracterizações de heroínas românticas, sobretudo na obra de Alencar. Porém, ela também era necessária à narrativa para que não pairasse sobre o protagonista nenhuma infame suspeita de ter casado com Guida apenas por dinheiro, atitude inaceitável num perfeito herói romântico.

Guida é, assim, uma das lindas amazonas mencionadas pelo narrador no começo do romance. Ela aparece montada num cavalo isabel, que é um cavalo de raça, originário da Inglaterra. $\mathrm{O}$ contraste entre as duas naturezas também aparece representado no contraste entre os dois cavalos: o cavalo britânico e nobre de Guida e o Galgo, o cavalo brasileiro mestiço de Ricardo e Fábio. O Galgo é descrito como fogoso e cheio de energia, enquanto que Edgard, o cavalo de Guida, é visto como um animal elegante, de raça pura, ou seja, modelada pelo homem. A diferença entre os dois cavalos é, então, testada em meio àquela face terrível da natureza:

\footnotetext{
Quem já foi à Pedra Bonita sabe quanto é abrupta aquela montanha; o caminho, bastante íngreme, atravessa encostas rudes, cortadas em rápido talude e profundamente sarjadas pelos sulcos das torrentes que descem do cimo da serra quando chove. Seria sumamente perigoso a descida por semelhantes barrancos, até mesmo para um animal solto.

$[\ldots]$

Guida ficou imóvel acompanhando com os olhos o "Galgo", que descia com admirável agilidade e firmeza o sinuoso barranco. Só havia para apoio do casco a estreita borda do sulco, por onde dificilmente andaria um homem a pé; e contudo o cavalo desceu e subiu sem vacilar um passo, com plena confiança na força e elasticidade de seus músculos (ALENCAR, s/d., p. 49).
}

Dessa forma, o cavalo Galgo apresenta um "parentesco", uma familiaridade com a face terrível da natureza. Ele é filho daquela natureza, ao contrário do cavalo britânico, que é um ente estranho àquele ambiente. $\mathrm{O}$ contraste entre as duas faces da natureza é alargada com o embate entre duas civilizações, a britânica e a brasileira. Nesse ponto, a natureza selvagem é vista como um elemento positivo, caracterizador de uma identidade, de um desejo de supremacia, que se torna visível na superioridade do cavalo brasileiro sobre o britânico na descida do penhasco da Pedra Bonita.

Consciente dessa necessidade de encontrar na natureza local elementos caracterizadores da identidade nacional, Alencar parece ter passado, na representação da natureza selvagem em Sonhos d'ouro, da ótica do sublime terrivel ao sublime magnífico. Logo surge a descrição da paisagem contemplada na "Vista dos Chins", recanto da Tijuca: 
campindo os horizontes do soberbo painel, o oceano calmo e sereno que se vinha desdobrar até babujar com branca orla de espuma as praias de Copacabana e de Marabaia. Era a Tela onde se estampava com vivo colorido, sobre o campo azul, a magnífica paisagem.

$[\ldots]$

Não vês junto ao sítio aprazível um enorme caramelo, servido sobre uma taça da mais pura safira, como a promessa dos regalos que a natureza americana oferece aos que visitam suas plagas?

É o Pão de Açúcar, no escorço a que o reduzem a distância e a eminência, donde o avistamos.

$[\ldots]$

O que porém dava a essa perspectiva um aspecto fascinador era sobretudo a diáfana limpidez do ar e uma plenitude de luz que estofava os objetos, cobrindo-os com uma espécie de áurea expansão. Não se podia chamar resplendor, porque não reverberava nem deslumbrava os olhos; era antes uma pubescência, doce e aveludada, onde se engolfavam os olhos com delícia (ALENCAR, s/d., p. 90)

Assim, há uma espécie de casamento entre o aspecto sublime e o aspecto pitoresco na natureza, já que é em meio a essa vista sublime que acontece o almoço entre os personagens que constituem o núcleo principal da narrativa, com o desenvolvimento de algumas tramas secundárias, como o relacionamento entre Fábio e D. Guilhermina, as trapalhadas de Mrs. Trowshy e do Sr. Daniel, bem como uma descrição mais elaborada do Sr. Benício.

\section{ESPAÇOS RESTRITOS}

Os espaços restritos funcionam nesse romance como complementares aos espaços amplos. Se, nesses últimos, são os sentimentos sociais que estão em foco, naqueles, há mais lugar para a intimidade, excetuando-se alguns jantares na casa de Guida que proporcionam a convivência social entre os personagens. Por não ser o nosso propósito um estudo exaustivo, selecionamos três momentos em que os espaços restritos nos parecem mais significativos no texto.

Uma das cenas mais relevantes que se dá num espaço restrito é aquela em que Guida se desespera em seu quarto após saber que Ricardo tem uma noiva em São Paulo. É esse o momento em que ela percebe pela primeira vez que está apaixonada por ele. O desespero por sabê-lo noivo havia sido controlado na presença do moço, sendo sufocado sob uma máscara serena, mas na solidão de seu quarto, Guida se permite gestos de grande dramaticidade:

Foi ao entrar no seu toucador, que o esto d'alma rompeu, como a onda por muito tempo comprimida. A moça levou as mãos ao seio que arfava a estalar com a ânsia, e caiu sobre o leito, escondendo o rosto nas fronhas de cambraia, comprimindo nas almofadas os quebros soluços. No seu desespero, espedaçou o vestido que a estringia como uma fôrma de bronze, e arremessou para longe de si os trapos da seda. Sobre as espáduas nuas desdobraram-se as cascatas dos opulentos cabelos negros, com que ela envolveu o colo e os seios, conchegando-se com um gesto pudico (ALENCAR, s/d., p. 135). 
O espaço restrito de seu quarto permite a Guida um extravasamento das emoções e uma posterior reflexão sobre os seus sentimentos. Também para o narrador é uma possibilidade de desnudar a personagem, sem ferir a moral dos leitores de sua época. Ele apresenta sua heroína com o colo e os seios nus, retirando dela todas aquelas sedas que a caracterizam como uma "moça elegante", portanto, bem diferente da "filha do deserto". Se, num primeiro momento, há no desnudamento uma aproximação entre os dois tipos de mulher - uma vez que arrancando a própria roupa, Guida assume uma atitude selvagem -, parece haver em seguida por parte do narrador e até da personagem uma contenção, uma volta ao pudor, quando ela esconde os seios e o colo nus com seus cabelos. De qualquer maneira, a sensualidade presente nesse trecho é única no livro e marca bem a transição de Guida, de menina inconsequente a mulher, através da paixão por Ricardo.

Outro momento digno de análise é a espécie de visão que Ricardo experimenta no sótão da casa onde passa a viver no segundo momento do livro:

\begin{abstract}
À tarde, fumando um charuto e sentado à janela do sótão donde avistava as verdes encostas de Santa Teresa e mais longe o Corcovado, o moço deixou-se ir à discrição do pensamento que o levava para os acontecimentos daquela manhã. [...] Imaginou-se outro homem, que não ele. Um moço pobre, de alguma inteligência, lutando corajosamente com a sorte, mas sem o vínculo de uma afeição, que o prendesse para sempre. Caminhava curvado ao peso do trabalho, quando uma voz celeste o chama. Ergue os olhos e vê descer das nuvens a moça mais gentil, deslumbrante de beleza, cintilando graça (ALENCAR, s/d., p. 147).
\end{abstract}

Nesse trecho também, o espaço restrito se apresenta como um espaço de confissão. Através desse devaneio, Ricardo confessa para si mesmo que deseja Guida, pela beleza e pureza da moça, mas também por sua riqueza. É interessante notar que o espaço restrito que envolve Ricardo não é um espaço qualquer, mas um sótão.

Gaston Bachelard (1993) entende a casa como um corpo de imagens que deve ser entendido na sua verticalidade, apresentando num mesmo eixo dois elementos opostos: o porão e o sótão. Para Bachelard, essa oposição permite duas perspectivas diferentes para uma fenomenologia da imaginação. O sótão e o porão, sendo ambos espaços da intimidade, possibilitariam o devaneio, a imaginação, mas cada qual a sua maneira. Assim, o sótão, mais próximo do telhado e do céu, se define, segundo Bachelard, como um local em que o "próprio sonhador sonha racionalmente", uma vez que "todos os pensamentos que se ligam ao telhado são claros” (BACHELARD, 1993, p. 31). O porão, inserido no subterrâneo, não tem acesso à luz, proporcionando devaneios mais sombrios e profundos. 
Utilizando esses conceitos como referência, podemos nos voltar para o devaneio de Ricardo com outros olhos. Esse devaneio representa no livro um verdadeiro rompimento de Ricardo com Bela, sem que seja necessário ao narrador submeter a personagem à quebra de sua promessa. A partir disso, o narrador se permite resolver essa questão através da correspondência entre os noivos. No sótão, estabelece-se, assim, o melhor caminho para a personagem. Ricardo, ainda que de forma sutil, já decidiu qual é a melhor alternativa para si mesmo. Daí até o casamento com Guida, é apenas questão de tempo, até que os últimos e menores obstáculos sejam retirados. Um outro espaço restrito também merece análise, mas por motivos diferentes dos dois primeiros trechos analisados. Trata-se da casa da avó de Guida, D. Leonarda:

\begin{abstract}
À tarde Guida lembrou-se de ir ver a avó no Andaraí. Aí vivia D. Leonarda retirada na chácara, onde nascera, no meio de uma récua de crioulas e um bando de moleques de todos os topes e de todas as cores. Aquela criação pululava e crescia à manga lassa, como bezerros do sertão sem freio e sem educação. D. Leonarda, desde que a serviam nos poucos misteres para os quais bastava uma criada diligente, deixava a troça das mucamas na mais complexa liberdade, até nove horas, em que punha-as todas, mães e avós de filhos, debaixo de chave, como donzelas recatadas; e nessa conta tinha-as todas, crendo realmente enjeitados pelas vizinhanças os moleques que the enchiam a casa (ALENCAR, s/d., p. 128-9).
\end{abstract}

A casa de D. Leonarda é representada como um ambiente de uma certa permissividade, com essas crianças "de todas as cores", indicando relações furtivas entre mulheres negras e homens brancos. Além disso, marca-se um olhar malicioso sobre as mucamas de D. Leonarda, que o narrador dá a entender que enganam a velha, tomando como enjeitados os próprios filhos. O narrador se utiliza mesmo da palavra liberdade. Segundo ele, D. Leonarda deixava as mucamas "na mais completa liberdade, até nove horas". Aí também percebe-se a malícia em relação às mulheres negras, que, sem a obrigação do trabalho, usariam a "liberdade" apenas para licenciosidades sexuais. No entanto, a casa de D. Leonarda se constitui num objeto relevante para o nosso estudo justamente por ser o único espaço na narrativa em que aparecem personagens negros, ainda que secundários. Também é importante ressaltar que é nesse cenário mais permissivo que Guida se permite, ainda que de maneira velada, propor ela mesma casamento a Ricardo. Nesse ambiente, tudo funciona para que a personagem fique um pouco mais livre das convenções sociais, que vedavam à mulher esse tipo de procedimento.

\title{
4 CONSIDERAÇÕES FINAIS
}

O espaço em Sonhos d'ouro se revela um elemento fundamental na construção da obra. A natureza do Rio de Janeiro é vista grandemente pela ótica da poética do pitoresco, proporcionando sítios aprazíveis para o encontro entre as personagens, aproximando, sem grandes obstáculos, moços pobres e moças ricas. Em outros momentos, a magnitude da natureza 
se impõe como elemento positivo, delineador de um desejo de identidade nacional. Nesses momentos, ela é retratada pela ótica da poética do sublime, sobretudo do sublime magnífico, que subjuga pela beleza.

Por outro lado, o autor também se preocupou em retratar alguns espaços íntimos, que revelassem o que se passava no íntimo das personagens. Foram escolhidos nesse estudo dois momentos importantes da intimidade dos protagonistas. A partir dessa relação espaço amplo espaço restrito, pôde-se entrever algumas fendas nas máscaras sociais das personagens. O exemplo mais intenso foi o caso de Guida, cujo desnudamento revelou um corpo de mulher e uma natureza ardente, numa menina que antes era descrita como alheia à paixão.

A casa de D. Leonarda mostrou, ainda que rapidamente, uma face da sociedade escravista do período. Nas palavras do narrador, percebe-se, como foi dito, um modo tendencioso de olhar a mulher negra, que mentiria e enganaria por malícia e não por necessidade. Num ambiente tomado por essa "malícia" das mulheres negras, o autor coloca Guida, uma mulher branca da sociedade, numa posição um pouco mais livre para expressar sua vontade ao homem. Nesse sentido, a casa de D. Leonarda também funciona como um espaço de confissão.

Assim, encerra-se o retrato da sociedade fluminense imperial proposto por Alencar. Uma natureza já domesticada não se opõe à reunião entre pares de classes sociais diferentes, auxiliando a ascensão dos jovens ambiciosos que passeiam por ela. Por outro lado, a natureza de um Brasil ainda meio indômito, uma paisagem marcada pelo sublime magnífico, pode ser encontrada não muito distante da cidade, revelando a sua proximidade com essas origens selvagens. Nos modos das moças e rapazes refinados, verifica-se a influência de valores e costumes estrangeiros. O Brasil seria, então, essa civilização híbrida entre o selvagem e o sofisticado, o antigo e o moderno, o sublime e o pitoresco. Para Alencar, a literatura brasileira deveria espelhar essa realidade e não imitar a tradição literária portuguesa, atingindo, assim, uma independência da imaginação e da criatividade.

\section{NOTAS}

1 Foi mantida a grafia do original.

2 Uma evidência disso é a própria situação de Ricardo, o protagonista, que não tem um cavalo só seu, tendo que dividir o Galgo com seu amigo Fábio.

3 Georg W. F. Hegel (2000) retoma a divisão realizada por Kant na experiência do sublime. Haveria o sublime terrivel, que provoca terror diante de forças que não podemos controlar; o sublime nobre, que se impõe pela consciência da dimensão do passado (como o que se experimenta diante de monumentos de civilizações já desaparecidas); e o sublime magnifico, que provoca um deslumbramento dos sentidos diante de uma organização magnífica da beleza. 


\section{REFERÊNCIAS}

ALENCAR, José de. Sonhos d'ouro. Rio de Janeiro: Ediouro, s/d.

ARGAN, Giulio C. Arte moderna. São Paulo: Companhia das Letras, 1993.

BACHELARD, Gaston. A poética do espaço. São Paulo: Martins Fontes, 1993.

CANDIDO, Antonio. Degradação do espaço. In: Revista de Letras, vol. XIV. Assis (SP), 1972, pp. 7-36.

HEGEL, Georg. W. F. Curso de estética. Volume II. São Paulo: Editora da Universidade de São Paulo, 2000 